\title{
PROTAGONISMO DO PENSAMENTO NEGRO NO BRASIL: O LUGAR DAS MULHERES E CRIANCAAS NEGRAS NO PROJETO UNESCO
}

\author{
ANA CRISTINA JUVENAL DA CRUZ ${ }^{*}$ \\ ORCID: https://orcid.org/0000-0002-8401-376X
}

RESUMO: Este artigo apresenta uma cartografia das pesquisas que trataram sobre a condição das mulheres e crianças negras no interior dos estudos que compuseram o programa de pesquisa da Organização das Nações Unidas para a Educação, Ciência e Cultura UNESCO aplicadono Brasil conhecido por "Projeto UNESCO" sobre relações raciais, em parceria com a Revista Anhembi de São Paulo entre 1950 e 1953. Debruçar-se-á sobre as descrições da etapa paulista do referido projeto cuja orientação a cargo de Florestan Fernandes e Roger Bastide, foi organizada metodologicamente com contribuições de mulheres e homens negros que atuaram também como pesquisadoras/es por meio de depoimentos e práticas empíricas de participação conjunta na investigação. De modo específico, serão apresentadas questões relativas à condição das mulheres e crianças negras, assim pretende-se reconhecer o protagonismo de negras e negros retirando-as do ostracismo a que foram relegadas.

Palavras Chave: Projeto Unesco. Crianças negras. Mulheres negras.

\section{BLACK THOUGHT'S PROTAGONISM IN BRAZIL: THE PLACE OF WOMEN AND BLACK CHILDREN IN THE UNESCO PROJECT}

ABSTRACT: This article presents a cartography of the researches about the condition of black women and black children within the studies that composed a research program about races applied in Brazil by the United Nations Educational, Scientific and Cultural Organization, known as "UNESCO Project". It was made in partnership with Revista Anhembi, of São Paulo, between 1950 and 1953. This text will focus on the descriptions of the Paulista stage of the project, whose orientation by Florestan Fernandes and Roger Bastide was methodologically organized with contributions from black women and black men who also acted as researchers through testimony and empirical practices of joint participation in research. Specifically, questions will be presented regarding the condition of black women and children, so it is intended to recognize the protagonism of black people by removing them from the ostracism to which they have been relegated. Keywords: UNESCO Project. Black children. Black women.

${ }^{1}$ Universidade Federal de São Carlos, São Carlos, SP, Brasil.

" Doutora em Educação, professora Adjunta na Universidade Federal de São Carlos (UFSCar), São Carlos SP, Brasil. Vice-Diretora do Centro de Educação e Ciências Humanas (CECH), membro do Núcleo de Estudos Afro-Brasileiros (NEAB/UFSCar). Email:< anacjcruz@ufscar.br > . 


\section{INTRODUC̣̃̃O}

Este artigo apresenta uma cartografia dos dados de pesquisas que trataram sobre mulheres e crianças negras no interior dos estudos que compuseram o programa de pesquisa da Organização das Nações Unidas para a Educação, Ciência e Cultura, UNESCO, realizado no Brasil conhecido por "Projeto UNESCO" sobre relações raciais, em parceria com a Revista Anhembi de São Paulo entre 1950 e 1953.

A Organização das Nações Unidas (ONU) é oficializada com essa designação em 1945, mas é proveniente da Liga das Nações - ou Sociedade das Nações (1919), uma organização de países extinta após o fracasso em impedir a Segunda Guerra Mundial - e da Organização de Cooperação Intelectual (OCI, 1921-1946). A própria nomenclatura utilizada reflete a concepção em torno de um desenho político pautado no fortalecimento do modelo do Estado-nação. O desenvolvimento da ONU surge em decorrência dos efeitos da Segunda Guerra Mundial, cujo objetivo era o de garantir a segurança e a paz em esfera internacional. Essa configuração ocasionou a necessidade de um instrumento regulador que agisse de modo a refrear possíveis conflitos entre as nações. Entre os princípios de atuação destaca-se o empenho na direção de garantir a soberania das nações, por meio da igual consideração e participação de seus membros. A UNESCO, dentre as agências da ONU possui uma centralidade atuar com certa autonomia em relação à $\mathrm{ONU}$, especialmente por determinar alguns dos temas que incidem sobre as outras agências que, por conseguinte, são inseridos na pauta interna das nações. É assim definida, por promover a cooperação no plano internacional, sustentando estudos com foco em descobertas recentes no campo da ciência para resolução de conflitos e tensões. Coube à UNESCO, desde a sua formação, a responsabilidade por um tema que ascendia como problemática a ser solucionada: a convivência entre povos e nações distintos quanto ao pertencimento étnico-racial e cultural.

Desde a sua composição, a UNESCO desenvolveu ações a fim de se consolidar como um fórum político no interior do Sistema das Nações Unidas com a finalidade de promover medidas normativas nas áreas da educação, ciência e cultura. A esfera de ação dos princípios da UNESCO, e das demais agências especializadas das Nações Unidas, aludiu-se à proteção do Estado-nação como uma unidade política. Tal concepção é herdeira de uma construção política moderna e ocidental que se aliou ao mote da busca pela "cultura da paz" (UNESCO, 2000; MAUREL, 2010). Especificamente, o princípio ancorou-se pela via de uma noção da convivência de relações sociais reguladas na tolerância 
e na compreensão entre as nações que garantiriam a soberania, o Estado de direito e a democracia, temas que foram impulsionados como um modelo de organização política internacionalizado.

Em 1950, a UNESCO lançou um informativo contendo itens e ações que seriam realizados naquele ano o mesmo em que a primeira Declaração sobre raça foi aprovada (UNESCO, 1950). O informativo veiculava uma pesquisa a ser realizada no Brasil, descrito como nação que, não obstante ter recebido grupos racialmente distintos, não exibia conflitos em termos de convivência quando contrastados com outras nações com distinta composição populacional no que tange a diferentes pertencimentos étnicos e raciais (UNESCO, 1950). A pesquisa teria o objetivo de oferecer, no âmbito dos conhecimentos das ciências sociais, informações sobre as condições que induzem a uma "situação desfavorável" e que poderiam auxiliar na construção de "relações inter-raciais mais pacíficas e felizes" (UNESCO, 1950, p. 4).

A alternativa pelo Brasil deu-se pela crença na representação, notadamente discursiva, do país como o lugar que havia suplantado conflitos raciais, algo que já se consolidava no interior da UNESCO (PARK, 1971). Em 1957, Roger Bastide publicou um artigo que apresentava as tendências em pesquisa sobre relações raciais nas Américas. Neste artigo, citou em destaque as investigações sobre a população negra realizadas no Brasil em especial as desenvolvidas no âmbito do projeto UNESCO. Segundo ele, o Brasil oferecia ao mundo um modelo de "democracia racial" cuja origem vinha das raízes de um tipo específico de relações construídas no seu passado escravista (BASTIDE, 1957, p. 525). Bastide afirmou que o estudo das relações raciais de uma dada formação social deveria ser realizado em análise com a "sociedade global" na qual se inseria desse modo, a articulação entre elementos emergiria nas análises sobre "preconceito de raça e preconceito de classe" (BASTIDE, 1957, p. 451). Bastide ainda apontou que no Brasil a "opinião pública é sensível ao bom nome do Brasil, a tudo o que poderia prejudicar a sua tradição de democracia racial" (BASTIDE, 1955, p. 124). Arthur Ramos alegava, com referência à tal tese, que o Brasil teria "a solução mais científica e mais humana para o problema, tão agudo entre outros povos, da mistura de raças e de culturas" (RAMOS, 1943 apud MAIO, 1997).

Tal semântica atuou como uma representação cujo conteúdo delineou a narrativa de uma presença, um determinado feitio brasileiro que poderia e deveria ser propagandeado ao mundo. Uma constituição alimentada pela construção de um arquétipo racialmente democrático não apenas da figura do brasileiro, mas do país como espaço onde 
habitavam pessoas com diferentes pertencimentos étnico-raciais conviviam harmonicamente sem conflitos (PAIXÃO, 2005). Essa interpretação, entretanto, foi extensamente criticada. Abdias do Nascimento apontou o "artificialismo de apresentar o Brasil no exterior como modelo de solução de convivência étnica" (NASCIMENTO, 1968, p. 74). Marcelo Paixão (2013) apontou como "moderna tradição culturalista" tal modelo de análise empregado em parte dos estudos sobre as relações raciais no Brasil que declina da análise positivada das relações raciais brasileiras cuja imagem é a mestiçagem, a partir do qual a variável cultural constituiu o bojo do projeto de Estado-nação e se tornou determinante nas leituras sobre as desigualdades raciais no Brasil.

Cornel West é aqui pertinente, quando afirma que "a maneira como estabelecemos os termos para debater os problemas raciais determina nossa percepção e reação a eles" (WEST, 1994, p. 19). Seguindo tal indicação, há uma opção por delinear alguns aspectos conceituais e metodológicos empregados nas pesquisas sobre as crianças e mulheres negras no Projeto UNESCO. Há nessa escolha algumas possíveis variáveis. É possível colocar os procedimentos empregados na investigação subvencionada como objeto de análise. Caberia ainda se debruçar sobre os temas e desdobramentos dos resultados encontrados. A abordagem aqui escolhida recai sobre a participação de pensadoras e intelectuais negras e negros como informantes e protagonistas no delineamento da pesquisa. O enfoque é cartografar algumas das investigações que trataram sobre mulheres e crianças negras no interior dos estudos subvencionados pela UNESCO no Brasil. Optei por tangenciar um caminho ao apontar pistas e trazer elementos à cena sobre os modos pelos quais pessoas negras pautaram o debate sobre a sua própria existência.

Ao cartografar as pesquisas que trataram sobre mulheres e crianças negras no interior dos estudos que compuseram o programa de pesquisa da UNESCO aplicado no Brasil em São Paulo entre 1950 e 1953, e especialmente sobre a participação de mulheres negras no escopo da pesquisa é possível estabelecer uma leitura que, além de dar indícios de um momento histórico específico da produção teórica brasileira, nos ofereça elementos para traçar um panorama amplo do pensamento social brasileiro a partir das falas de mulheres negras sobre sua condição e sobre as relações entre as crianças.

No caso da participação das mulheres negras este intento se alia, seja às pesquisas que estão articulando métodos da história de vida ou de história intelectual, na recolocação dessas mulheres como artífices de um processo de produção acadêmica e intelectual negra no 
Brasil. Isso tem permitido recolocar sob outras bases a relação entre o pensamento intelectual e a ação política no âmbito das associações negras uma vez que a maioria dessas mulheres esteve vinculada a alguma associação negra e realizando a atividade intelectual. Há que se questionar por que essas mulheres foram alocadas na invisibilidade e na proscrição e assim deslindar a escrita da história que ignora e omite a participação das mulheres negras (DAVIS, 2017).

Ao repertoriar essas impressões há uma inflexão temporal que apresenta não apenas a atualidade do tema, mas questões que se colocam na contemporaneidade. $\mathrm{Na}$ opção metodológica aqui empregada, ao cartografar essas pesquisas em um modo diacrônico e histórico o debate contemporâneo é substancializado, ou seja, o argumento central aqui delineado é de que essas pesquisas nos informam mais sobre a atualidade do tema uma vez que expõem a invisibilidade a qual essas pesquisas foram relegadas. Dito de outro modo, cartografar essas pesquisas permite posicioná-las de maneira a conciliá-las sob uma utilização conceitual diaspórica, uma vez que o conceito de diáspora integra não apenas as rotas de dispersão, mas os modos de construção de outras configurações temporais o que oportuniza aproximar diferentes acontecimentos (BRAH, 2011, p. 50).

Com isso, é possível rastrear uma lacuna nas leituras realizadas acerca do Projeto UNESCO uma vez que os modos como o preconceito racial atravessava as relações entre crianças e a condição das mulheres negras foi negligenciada em grande parte das análises realizadas pelos pesquisadores vinculados ao projeto como investigadores. Isso se justifica em grande parte, pois é consenso de que o Projeto UNESCO instituiu não apenas um empreendimento acadêmico, mas um espaço de produção teórica sobre as questões étnicas e raciais brasileiras à época. É necessário acrescentar a essa realização o protagonismo do pensamento negro.

\section{OS TEMAS DO PROJETO UNESCO SOBRE AS RELAC̣ÕES RACIAIS BRASILEIRAS}

A proposta ${ }^{1}$ da UNESCO em realizar uma ampla investigação sobre relações raciais configurou-se em um "programa de difusão de fatos científicos destinados a fazer desaparecer o que se convencionou chamar de preconceito de raça" (PINTO apud MAIO, 1999). Concretizado em diferentes etapas, o programa contou com a idealização de Alfred Métraux, que atuava pela UNESCO e a Revista Anhembi integrada pelos esforços de Paulo Duarte, que atuou como seu editor e aspirava "patrocinar um inquérito em profundidade sôbre o problema do negro 
em S. Paulo" (DUARTE, 1955, p. 7, sic). A publicação dos dados da pesquisa na Revista Anhembi ocorreu com o objetivo de divulgar uma "investigação sociológica no Brasil cientificamente orientada", sobretudo a partir da repercussão de um artigo publicado por Duarte no jornal " $\mathrm{O}$ Estado de São Paulo” em $1947^{2}$ (DUARTE, 1955, p. 7). Neste artigo, em uma crítica aos efeitos do Estado Novo, apregoa resenhar o "problema do negro" que se constituía, segundo ele, em parte pela falta de acesso à educação primária e, igualmente, pela exposição a "endemias patológicas ou sociais" derivadas dos "recalques da escravidão" (DUARTE, OESP 16/ABRIL/1947, p. 5, sic). No decorrer do artigo Paulo Duarte contesta frontalmente as proposições de um tipo representativo de brasileiro com fenótipo que caracterizava a mestiçagem construída a partir de uma sociologia idealizada por Gilberto Freyre. Para Duarte, a sociologia de Freyre era uma "pequena sociologia do nordeste que procura impor como verdade científica, o romantismo mestiço de que o tipo característico do brasileiro é o mulato" (DUARTE, OESP - 16/ABRIL/1947, p. 5, sic).

A contestação de Paulo Duarte se dirigia, principalmente na investida em um tipo brasileiro que figurava na "sociologia nigroromântica do nordeste" (DUARTE, OESP - 16/ABRIL/1947, p. 5, sic). Em outras palavras, a crítica de Duarte se deslocava da construção do brasileiro como uma figura miscigenada entre o branco, o negro e o índio. Segundo Duarte, tal leitura colidia com "a deliberação marcada pelo consenso unânime dos brasileiros lúcidos: o Brasil quer ser um país branco e não um país negro" e prossegue:

"Não vem aqui agora o estudo ou a pesquisa destinada a saber se o negro é intelectual ou moralmente inferior ao branco, ou ao índio, se o branco ou o índio são menos primitivos ou mais adiantados do que o negro. O que prevalece é a decisão brasileira de ser um país branco e mais nada" (DUARTE, OESP - 16/ ABRIL/1947, p. 6, sic).

Ao descrever a substancialidade da mudança estrutural e a pressuposição no desaparecimento gradativo do negro em consequência de que:

O branco é que vai absorver o negro e não o negro, que, no futuro, tenha que prevalecer sobre o branco. Não vai nisso nenhum desprezo pelo negro, nem desprezo coletivo da parte da maioria branca, do povo brasileiro, nem pessoal do alinhavador destas linhas. É decisão expressa de um país em pleno processo de evolução e desenvolvimento, propósito coletivo que a investigação e os documentos sociológicos permitem hoje seja afirmado com certeza absoluta (DUARTE, OESP - 16/ABRIL/1947, p. 5, sic).

A convicção de Paulo Duarte camuflava certo "imaginário do medo" (AZEVEDO, 1987) face aos conflitos entre negros e brancos: 
Devido a erros iguais ou maiores, não podemos retrogradar agora, em meio de perigo pior que é a desorientação da população negra, que, abandonada na sua miséria física e moral, começa a constituir uma ameaça para o branco, criando situação inversa daquela que se podia esperar, isto é, o preconceito do negro contra o branco, absolutamente pacífico e cordial em face de seu compatriota de cor (DUARTE, OESP - 16/ABRIL/1947, p. 6, sic)

O saudosismo irrefletido de Duarte expressava-se pelo desaparecimento do "tipo tradicional de negro bom" cristalizado pela "lembrança a memória agradável das velhas empregadas negras tidas como pessoas da família” (DUARTE, OESP - 16/ABRIL/1947, p. 6, sic).

Muitas lideranças e pensadores do Movimento Negro se opuseram às ideias de Duarte neste artigo, no Jornal Alvorada em 1947, José Correia Leite afirma:

\footnotetext{
"apavorado e lúgubre, tresandando a miasma do escravagismo, como um senhor antigo na casa grande (...) o Sr. Paulo Duarte veio do exílio com ranços de arianismo. Não conhece mais o seu Brasil mestiço. Responsabiliza o 'Estado Novo' pelo desrespeito (?) que o negro vem demonstrando contra os brancos. E esquece que a mística desse regime afetou, desde os mais altos de nossa cultura, quanto mais os da raça semi-analfabeta." (Jornal da Alvorada, 1947, sic).
}

Esse debate sobre os modos em que a população negra, especialmente seu comportamento social, são descritos irão impactar no delineamento da pesquisa a ser desenvolvida. As reações frente às declarações de Paulo Duarte indicam que o campo de realização das pesquisas seria um campo de disputa.

\section{O DESENVOLVIMENTO DA PESQUISA EM SÃO PAULO}

Florestan Fernandes e Roger Bastide, na descrição da etapa paulista do projeto no texto "O preconceito racial em São Paulo (projeto de estudo)", delinearam os trajetos e apontaram um dos objetivos da pesquisa em descortinar o "preconceito de côr" (sic) na cidade de São Paulo. Ao apresentar os aspectos metodológicos, os autores expuseram o caráter do projeto de ser "informativo, descritivo e interpretativo" e as problemáticas de se analisar o preconceito baseado na cor da pele como objeto de pesquisa na medida em que sua "natureza e função estão longe de ser bem conhecidos pela Sociologia” (BASTIDE; FERNANDES, 1959[1959]).

O livro Relaçoes raciais entre negros e brancos em São Paulo, publicado pela Editora Anhembi em 1955 com os resultados integrais das investigações realizadas - ao contrário da proposta da UNESCO de publicar as pesquisas em formato de brochuras de no máximo cem páginas - apresentou a descrição e alguns dados do contexto paulista ${ }^{3}$ que complementavam os outros artigos da pesquisa já publicados na Revista Anhembi. 
$\mathrm{Na}$ estrutura da pesquisa realizada em São Paulo, Bastide e Florestan conduzidos por pressupostos metodológicos de pesquisa realizada pela sociologia norte-americana, seguiram a sugestão do "preparo de pesquisas pessoais por uma reunião coletiva, a fim de que todos possam compreender o interesse e as razões das perguntas feitas" desse modo, "reuniram-se numa mesa-redonda os representantes mais qualificados dos paulistas de cor" (BASTIDE, 2008 [1955], p. 21). Bastide afirmou a necessidade de uma metodologia plural com foco nas ações dos participantes, na medida em que seria "mais difícil descobrir o que pode estar oculto sob a indiferença, as omissões ou as faltas. Será preciso recorrer, muitas vezes, não à análise de comportamentos, mas à da ausência de comportamentos" (BASTIDE, 1955, p. 124).

Após essa primeira reunião coletiva foram definidas comissões específicas, como: "Comissão para o estudo das relações entre brancos e pretos em São Paulo", "Comissão especial de alguns intelectuais de cor" e "Comissão do Estudo da Mulher Negra em S. Paulo", descrita como "Comissão feminina encarregada de examinar os característicos do preconceito de côr e que se reunia quinzenalmente no gabinete I da Cadeira de Sociologia" (BASTIDE, 2008 [1955], p. 22, sic).

Ao longo dos encontros realizados nessas Comissões, os coordenadores da pesquisa identificaram obstáculos na aquisição dos dados, especialmente em virtude da dificuldade de avaliar concomitantemente as falas de todos/as os participantes. No período de ida à campo, Florestan sugeriu a opção por procedimentos de pesquisa como observação participante e análise de situações grupais, a fim de captar por meio das falas "o aprofundamento perceptivo e cognitivo do negro sobre sua condição humana" (FERNANDES, apud, MAIO, 1997, p. 126). Inovadora no que se refere à opção metodológica, o uso dessas técnicas de "observação participante em situação grupal" foram pioneiras em uma investigação desta natureza (BASTIDE, 1955, p. 260).

Antônio Candido (1987) afirmou sobre a pesquisa UNESCO em São Paulo:

"[...] a tarefa decisiva dos anos 50 se ordenou em torno do negro, pois naquela altura ele [Florestan] aceitou participar com Roger Bastide na direção de uma pesquisa da Unesco sobre as relações raciais entre brancos e negros em São Paulo. [...] Com efeito, o negro não era algo remoto como o Tupinambá, mas um cidadão vivendo ao nosso lado, espoliado, vítima do preconceito, participando da mesma dinâmica social que nós. Daí talvez a pesquisa da Unesco ter sido uma oportunidade para Florestan desenvolver formas extremamente participantes de Sociologia. Basta lembrar alguns aspectos do método que usou, como as reuniões 
promovidas entre líderes e militantes negros, junto com os seus colaboradores e outros interessados. Com isso estava dando simultaneamente aos negros certa forma de consciência política e de organização. E ainda mais: a partir da compreensão dos problemas deles, estava amadurecendo a maneira do intelectual intervir na sociedade que gerava tais problemas (CANDIDO, 1987, p. 34-35).

Assim, segundo Candido, a pesquisa "se fez com extraordinária mobilização dos grupos negros, que graças a ela tiveram a rara oportunidade de manifestar os seus problemas e a sua angustiosa situação" (CANDIDO, apud, MAIO, 1997, p. 125).

As contribuições de homens e mulheres negras atuando como informantes e participantes foram captadas pelo uso de técnicas e procedimentos metodológicos que, nos encontros das Comissões, aprimoraram a "observação em massa" a partir da qual as sugestões foram incorporadas. Assim Florestan descreve:

Graças ao prestígio de Bastide na comunidade negra, contamos com uma maciça colaboração de negros e mulatos de várias categorias sociais e das diferentes gerações em contato. [...] Tínhamos a intenção de coligir documentos pessoais, elaborados pelos próprios sujeitos. O nível médio de escolaridade e de maturidade intelectual mostrou que só alguns sujeitos estavam em condições de nos proporcionar os materiais desejados. Isso nos obrigou a uma tática rica de investigação. Substituímos o documento pessoal (mantido para um número pequeno de sujeitos) pela observação participante em situação grupal (o que aumentou o interesse daquelas reuniões e dos materiais estenográficos resultantes). E logo empreendemos reuniões paralelas com as mulheres (que se revelaram mais maduras que os homens na percepção da realidade ambiente) e com os intelectuais negros (que se tornaram também pesquisadores, elaborando estudos de caso especiais) (FLORESTAN, 1989 apud CAMPOS, 2014).

\section{CONSTRUINDO PONTOS DE VISTA}

A fim de estabelecer elementos para uma cartografia da pesquisa sobre a condição de mulheres e crianças negras no Projeto UNESCO, o enfoque se deu em documentos, artigos, livros e materiais coletados no Fundo Florestan Fernandes localizado na Biblioteca Comunitária da Universidade Federal de São Carlos que possui acervo da vida de Florestan Fernandes. Com o propósito de sintonizar com a escrita do momento histórico de produção dos documentos manteve-se a descrição literal no que tange à descrição do pertencimento étnico-racial de "pretos", negros, brancos, mulatos e "de cor". ${ }^{4}$ As citações e a paginações dos documentos preserva a do PDF onde se encontra na organização do Fundo Florestan Fernandes 
assim mantém-se o princípio da proveniência de modo a manter os documentos originalmente como foram encontrados (COSCIA, 2011). Ressalta-se que a citação dos documentos segue rigorosamente conforme estão digitalizadas e preservadas nos arquivos em PDF, portanto, mantém-se a cópia literal da escrita. ${ }^{5}$

Os encontros foram denominados "mesa redonda", a primeira está assim redigida: "Mesa Redonda sôbre o Preconceito Racial no Brasil, realizada na Biblioteca Municipal, no dia 8 de maio de 1951, patrocinada pela UNESCO, sob presidência do Prof. Roger

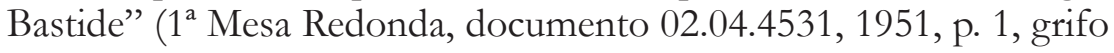
no original). A descrição da mesa inicia com a fala de Roger Bastide:

O sr. Carneiro, que é o Representante do Brasil na Organização Cultural das Nações Unidas, a UNESCO, pediu que se faça um estudo sobre as relações raciais no Brasil, particularmente no Sul e parte do Norte, para mostrar como se pode encontrar um caminho, de solução mesmo, para o problema racial nos Estados Unidos. E assim, aqui em São Paulo, uma pequena Comissão de Professores, Cientistas e Intelectuais foi criada para estudar o preconceito de côr, as barreiras raciais, as ideologias, de brancos e pretos e para estudar também se há alguma dificuldade, um estudo de problemas, aqui na cidade industrializada onde a população estrangeira também é muito importante. Falando com meu Amigo Jorge Teixeira, êle teve a idéia muito feliz, de fazer uma Mesa Redonda, para discutir entre nós êste preconceito de côr, ou da existência de miscigenação racial asiática. Foi por isso que eu pedi o comparecimento de alguns intelectuais negros e dos lideres de côr, assim como de alguns estudantes brancos que se interessam pelo problema racial ( $1^{\text {a }}$ Mesa Redonda, Roger Bastide, documento 02.04.4531, 1951, p. 1, sic).

Na sequência, Florestan Fernandes estabeleceu as etapas de realização da pesquisa apontando as limitações de seguirmeticulosamente a metodologia sugerida de participação dos depoentes na pesquisa como já havia sido empregado em outras pesquisas semelhantes na Inglaterra. Deste modo, Florestan sugeriu que os participantes escrevessem um documento no qual relatassem as experiências vivenciadas em São Paulo. O material deveria ser manipulado sem identificação, mas seria constituído como "um documento pessoal, referente a situação do negro, em geral, em São Paulo" (1 $1^{a}$ Mesa Redonda, Florestan Fernandes, documento 02.04.4531, 1951, p. 8).

A descrição da expectativa em relação aos dados aponta alguns dos temas que posteriormente apareceriam nas obras de alguns dos acadêmicos participantes do projeto:

Os senhores nos dariam a possibilidade de esclarecer a situação do negro em São Paulo; quais são as relações dos brancos com os pretos; quais são as barreiras que os pretos encontram quando êles pretendem fazer uma carreira igual à dos brancos; até que ponto o branco se comporta para com o preto; existe ou não preconceito de côr 
em São Paulo, até que ponto tem prejudicado a situação social e econômica dos pretos e como segundo os senhores pensarem, nós poderíamos modificar essa situação? $\left(1^{\mathrm{a}}\right.$ Mesa Redonda, Florestan Fernandes, documento 02.04.4531, 1951, p. 9, sic).

Florestan ainda indica os procedimentos de participação de uma "comunidade negra, que possue elementos de grande envergadura intelectual" (1 $1^{\text {a }}$ Mesa Redonda, Florestan Fernandes, documento $02.04 .4531,1951$, p. 9, sic):

[...] nós pensamos que podiamos transformar a pesquisa no sentido de aproveitarmos a contribuição que os próprios pesquisados poderiam nos trazer. Essa experiência de aproveitar o pesquisado, de transformar a pesquisa, da participação e colaboração, tendo em vista a experiência que já foi realizada fora do Brasil, na Inglaterra que deu resultados muito interessantes, permitirá ver os problemas, não no ângulo do especialista que pode ter a mente mais ou menos limitada, mas no ângulo do observador ( $1^{\mathrm{a}}$ Mesa Redonda, Florestan Fernandes, documento 02.04.4531, 1951, p. 9, sic).

O Sr. Pedro de Alcântara questiona a participação na investigação e a relação com a UNESCO:

"Sr. Presidente. Nós nos sentimos honrados com o vosso convite para esta assembleia mas, eu apenas queria que V.Exia. nos respondesse: conhecidos êsses quesitos, qual será o resultado? Conhecido o resultado da pesquisa, a UNESCO o que vai fazer conosco?" (1 $1^{a}$ Mesa Redonda, Pedro de Alcântara, documento 02.04.4531, 1951, p. 22, sic).

Tal questão explicitada salienta inquietações com o futuro da pesquisa e de seu objetivo. O questionamento em torno de como os dados seriam obtidos e utilizados bem como qual o papel da UNESCO nesse processo demonstra um pensamento a longo prazo dos impactos da pesquisa. Jorge Teixeira indica que Florestan Fernandes teria mais condições de explicar os objetivos da UNESCO que ele indica serem da ordem do "trabalho social e assistência social" ( $1^{\text {a }}$ Mesa Redonda, Florestan Fernandes, documento 02.04.4531, 1951, p. 9, sic). Explana longamente o desejo da UNESCO de conhecer a "situação de contato" entre negros e brancos no Brasil para servir de modelo às suas ações e a outros países.

\section{A DIMENSÃO RACIAL NAS RELAC̣ÕES ENTRE CRIANC̣AS}

Florestan Fernandes ainda na primeira mesa redonda fez referência às investigações que utilizariam aportes da psicologia na pesquisa:

O projeto inicial da UNESCO é um projeto circunscrito e não visa estudar toda a comunidade negra em São Paulo, no Rio de Janeiro e na Bahia. [...] No que concerne a São Paulo, o Prof. Bastide se encarregou do planejamento das pesquisas 
que vão ser efetuadas. Estas vão abranger uma parte que será psicológica e que vai ser feita pela Profa. Virgínia Leoni Bicudo. A parte sociológica está dividida em duas partes, que serão feitas na Capital por mim e pelo Prof. Bastide e a outra que será feita em Itapetininga, pelo Prof. Oracy Nogueira ( $1^{\mathrm{a}}$ Mesa Redonda, Florestan Fernandes, documento 02.04.4531, 1951, p. 4).

As pesquisas sobre criança e infância embora tivessem sido identificadas e reconhecidas como pertencentes ao Projeto UNESCO o foram apenas incorporadas como "protocolos de pesquisa". Essas pesquisas foram realizadas por Virgínia Leone Bicudo e Aniela Meyer Ginsberg. Virgínia Leone Bicudo ${ }^{6}$ a partir de seu percurso como pesquisadora e docente na Escola de Sociologia e Política de São Paulo integrou o projeto sendo a única mulher negra ${ }^{7}$ a compor a equipe de pesquisa. Bicudo figura no corpo de pesquisadores e pesquisadoras com uma pesquisa acadêmica finalizada no escopo dos resultados publicados pela Revista Anhembi. A autora publica "Atitudes dos alunos dos grupos escolares em relação com a côr dos seus colegas" " cujo objetivo foi o de analisar "os sentimentos e os mecanismos de defesa nas atitudes relacionadas com a côr dos colegas" (BICUDO, 1955, p. 227 sic). A partir de um universo de 4.320 alunos de escolas da cidade de São Paulo, Bicudo submeteu esses alunos a um questionário com a finalidade de coletar dados "referentes aos sentimentos, aos estereótipos e às atitudes entre os brancos e os de côr" (BICUDO, 1955, p. 228 sic).

Em frente análoga de investigação, Aniela Meyer Ginsberg ${ }^{9}$ apresenta a investigação "Pesquisas sôbre as atitudes de um grupo de escolares de São Paulo em relação com as crianças de côr" (1955) onde estudou "a atitude das crianças de idade escolar para com os seus colegas brancos e de côr" a partir dos marcadores de "idade, sexo, meio social, e a côr dos examinados" (GINSBERG, 1955, p. 311, sic)..$^{10}$ Aniela foi indicada por Otto Klineberg que trabalhou no Brasil entre 1943 e 1947 e a recomendou como psicóloga social para o Projeto UNESCO.

$\mathrm{Na}$ primeira mesa redonda o Dr. Ângelo Abataiguara, fez referência há uma investigação realizada com crianças de estabelecimentos escolares: "Em 1938 fiz nos grupos escolares uma pesquisa em massa. Tenho cerca de 2 mil observações. Assim eu cheguei a conclusão de que existe um preconceito de cor artificial, trazido pelos estrangeiros" $\left(1^{\mathrm{a}}\right.$ Mesa Redonda, Ângelo Abataiguara, documento 02.04.4531, 1951, p. 42, sic). Percebe-se, portanto que o espaço escolar, anteriormente, já era visualizado como espaço fecundo de análise social no que tange à busca do conhecimento acerca do preconceito racial. É evidente, portanto que o olhar sobre as crianças e suas relações aflora na pesquisa realizada por Ângelo Atabaiguara, na medida em que Aniela Meyer e Virgínia Bicudo utilizam em suas pesquisas o termo "escolares" para se referir a crianças 
que frequentam o espaço escolar. Ou seja, essa citação de Atabaiguara nos mostra que a pesquisa sobre as relações sociais entre crianças existe anteriormente à temporalidade utilizada na contemporaneidade visto que ele afirma que sua pesquisa data de 1938.

Francisco Lucrécio fez menção à pesquisa empírica realizada com crianças em Parques Infantis da capital paulista sobre o preconceito racial e as relações sociais entre as crianças (CRUZ, et. al. 2015).

Estão fazendo pesquisa sociológica. Achei conveniente trazer também a minha contribuição. Fala-se do preconceito que se manifesta desde os bancos escolares. Eu acho que é o problema mais importante, e que nós devemos atacá-lo rijamente. As crianças que frequentam não só os bancos escolares, as escolas particulares, bem assim como os parques infantis, eu tive oportunidade de observar que as crianças pretas não são tratadas como as crianças brancas. [...] Se nos parques infantis, em que são acolhidas as crianças, em sua maioria, filhos de operários, observamos que as crianças brancas têm todo o apoio e acatamento dos educadores, entretanto, as criancinhas negras ficam por alí, acompanhando os outros, sem que sejam acolhidas do mesmo modo. Isto prova que o preconceito inicia-se desde o banco escolar, já incutindo no espírito da criança a situação de obediência e inferioridade. Pesquisas nessas escolas, mesmo quanto à orientação do mestre, seria de grande valor, porquanto nos já atacaríamos o assunto. Portanto, está provado, mais uma vez que o preconceito inicia-se desde quando a criança frequenta os bancos escolares. Tenho dito (2a Mesa Redonda, Francisco Lucrécio, documento 02.04.4531, 1951, p. 98, sic).

Presume-se a partir dessa observação, que havia uma distinção às quais as crianças negras que frequentavam os Parques Infantis eram submetidas e que, portanto, necessitavam de uma análise sociológica. Além de demonstrar o despreparo de profissionais no trato com as crianças negras, ao relatar os casos observados nos Parques Infantis de São Paulo cuja função principal era de acolhimento das crianças operárias e pobres, - portanto em número considerável, negras - expõe que esse espaço não acolhia de maneira igualitária as crianças negras e brancas. Em outras palavras, havia um atravessamento racial no interior dos Parques Infantis que refletia os preconceitos e discriminações raciais identificadas no corpo social da cidade de São Paulo. Ou seja, o atendimento desenvolvido nesses espaços era transverso à questão racial atingindo diferentemente crianças negras e brancas.

\section{A COMISSÃO FEMININA: AS MULHERES NEGRAS}

O documento contendo a descrição da segunda mesa redonda está assim relatado: "Segunda mesa redonda sôbre o preconceito racial no Brasil, realizada no Salão Nobre Da Faculdade de Filosofia Ciências e Letras da Universidade de São Paulo, no dia 5 de junho de 1951, 
patrocinada pela UNESCO sob a presidência da Sra. Ruth De Souza" ( $2^{\mathrm{a}}$ Mesa Redonda, documento 02.04.4531, 1951, p. 64, sic, grifo no original).

Roger Bastide iniciou a reunião chamando Ruth de Souza, célebre atriz brasileira e integrante do Teatro Experimental do Negro (TEN), para compor a mesa "como homenagem à mulher de côr" ( $2^{\mathrm{a}}$ Mesa Redonda, Roger Bastide, documento 02.04.4531, 1951, p. 64, sic). Em seguida passou-se a discutir, ainda como decorrência da Primeira Mesa Redonda, questões acerca do uso das metodologias de observação em massa e da elaboração dos questionários a serem aplicados. Há a indicação da criação de uma Comissão de Pesquisa e uma Comissão de Redação que ficaria responsável pelo cuidado com os dados encontrados. ${ }^{11}$

Ao tomar a palavra, Virgínia Bicudo propôs a realização de um encontro à parte com a participação prioritária de mulheres negras: "Gostaria de convidar o elemento feminino para uma reunião, para que pudessemos juntas trabalhar. Peço sujestão, em primeiro lugar, de dia e hora que sejam mais convenientes para os elementos femininos" ( $2^{\text {a }}$ Mesa Redonda, Virgínia Leone Bicudo, documento 02.04.4531, 1951, p.66, sic) Bastide comenta acerca da criação de uma comissão de mulheres negras:

Trata-se da comissão feminina para análise da mulher negra brasileira. Trata-se de uma comissão que encarregar-se-á única e exclusivamente de situar esta questão; de estudar esse problema, um problema gritante em todos os pontos, porquanto a mulher negra sob certo ponto de vista é a que sofre mais. Dessa maneira essa comissão feminina poderia ser integrada de principio e integrando naturalmente a apresentação de outros nomes - pelas sras. Profa. Virgínia Bicudo, Sofia Campos Teixeira, Profa. Aparecida Camargo e pela renomada atriz Ruth de Souza (2 $2^{\mathrm{a}}$ Mesa Redonda, Roger Bastide, documento 02.04.4531, 1951, p. 84, sic).

Antes do final da sessão da quinta mesa redonda, ${ }^{12}$ Jorge Teixeira fez um comunicado sobre a Comissão feminina:

Peço licença ante essa interrupção, seja um assunto importante; trata-se de uma comissão feminina que nós estamos formando para discutirmos sôbre a situação da mulher negra, de uma maneira mais ou menos especifica. Essas reuniões têm sido realizadas na Faculdade de Filosofia. Apelo à todas as Senhoras presentes que queiras prestar sua colaboração, no sentido de ilucidar melhor o assunto, que entrem em contacto com a Profa. Sofia de Campos, srta. Aparecida Camargo ou srta. Maria Helena Barbosa para que com elas seja o grupo formado de modo a dar um ritmo melhor às atividades da Comissão Feminina ( $5^{\mathrm{a}}$ Mesa Redonda, Jorge Teixeira, documento 02.04.4531, 1951, p. 274, sic).

Percebe-se nesses excertos que havia uma compreensão da condição especial e diferenciada em torno da presença das mulheres negras. Houve, portanto, negociações internas com a participação das 
mulheres negras que garantiram a sua participação. Tais afirmações mostram que havia uma análise de que o preconceito racial experienciado pela população negra ocorria de forma distinta entre as mulheres. Foram recomendados ainda mais nomes para participação na "Comissão Feminina" 13 que foram colocados em debate havendo a indicação de realizaçãode uma reunião posteriorpara eleiçãoentreas mulheres indicadas. Houve uma discussão entre os homens presentes sobre a necessidade de uma comissão específica de mulheres, por haver um entendimento que os problemas das mulheres negras ocorriam sincronicamente ao dos homens negros. Em seguida, Ruth de Souza foi convidada a declamar um poema e, posteriormente, deu-se prosseguimento aos trabalhos do dia. Francisco Moraes ao ter retomado a fala não finalizada na Primeira Mesa Redonda descreveu casos de preconceito para justificar a existência do mesmo e, em um momento diz: "Dificilmente negrinhas conseguem matrículas nas escolas" ( $2^{\text {a }}$ Mesa Redonda, Francisco Moraes, documento 02.04.4531, 1951, p. 92, sic).

O documento "Reunião das Senhoras de Côr, realizada na Faculdade de Filosofia, dia 14 de Agosto às 20:30 Horas" ${ }^{14}$ descreve em subtemas as relações interpessoais, profissionais, das causas e motivações que levam a relacionamentos afetivos inter-raciais com perguntas e respostas diretivas sobre os temas do preconceito racial do ponto de vista das mulheres negras. São mencionadas nesse encontro as presenças de Maria Nascimento, Nair Ribeiro, Sofia Campos todas intituladas Professoras e Edila Nogueira intitulada à profissão de costureira, participam também Dr. Arlindo Veiga dos Santos. O formato é de uma entrevista coletiva na qual são descritas as perguntas e as respostas das participantes. Com relação à questão acerca da existência do "preconceito de côr":

Existe. Não precisa explicação; basta ver por exemplo, andar pelas ruas da cidade e ver se encontra moças de côr trabalhando nas lojas e, mesmo as compradoras de côr, nem sempre são atendidas. É a ação do preconceito, naturalmente, em algumas casas. É o preconceito, por exemplo, do contacto entre brancos e pretos (Reunião das Senhoras de Côr, Maria Nascimento, documento 02.04.4254, 1951, p. 1, sic).

A fala acima reproduzida aponta para a inserção no debate teórico dos modos de operacionalização do preconceito e da discriminação racial em diferentes esferas da vida social paulistana naquele período histórico. As entrevistas indicam rejeição em aceitar mulheres negras em determinadas profissões o que dá indícios de que esses impedimentos de cunho racial levaram as mulheres negras para determinados tipos de profissão impedindo seu acesso a atividades laborais que poderiam fazê-las ascender socialmente. 
Maria Nascimento relatou suas impressões no desenvolvimento de seu trabalho na Fundação Leão XIII: ${ }^{15}$ "Quando se tratava de internar uma pessoa branca, não havia dificuldade porém, quando era mociça de côr, havia grande dificuldade. Preto podia morrer (Reunião das Senhoras de Côr, Maria Nascimento, documento 02.04.4254, 1951, p. 3, sic). Esse trecho é demonstrativo de uma regularização de uma prática que aponta uma determinada concepção. A expressão "Preto podia morrer" aponta a condição da falta de acesso a um serviço público que ocorria de forma regular. Havia, portanto, uma lógica que impedia o acesso das pessoas negras em políticas públicas cujo objetivo era de dar assistência à população pobre.

Edila Nogueira ao ser questionada sobre as relações no grupo escolar que então frequentava na Escola Profissional -Associação Cívica Feminina ${ }^{16}$ afirmou:

\footnotetext{
Um dia na Casa da Ruth, à Rua Barão de Itapetininga, onde trabalhava, a patroa queria que eu fosse levar a menina dela para casa. Eu respondi: - Não vou porque não sou pagem - A patroa retrucou: - Sua negrinha! Você vai ou não vai? - Não vou. - Você pode ir embora então. [...] Saí na mesma hora. [...] Fiquei irritada com ela. Era uma senhora sem educação, portanto, não senti. Se fosse uma pessoa educada, ficaria sentida. (Reunião das Senhoras de Côr, Edila Nogueira, documento $02.04 .4254,1951$, p. 1, sic).
}

Essa situação demostra um conflito racial e da hierarquia das relações de trabalho. Ao se negar a realizar a tarefa solicitada, a entrevistada é vítima de injúria racial. A postura de recusa e posterior abandono daquela relação mostra uma postura de altivez frente ao ato discriminatório. A justificativa é ainda elucidativa de uma concepção de que o preconceito e a discriminação competiam às pessoas "sem educação" e a entrevistada ao perceber que a pessoa em questão não era educada e, portanto, não obtinha elementos para se relacionar socialmente não se ressentiu ao acontecido.

Nair Pinheiro analisa o caso afirmando que "Geralmente, quando falam negrinha, falam com desprezo. O tratamento de negrinha, partido de pessoa branca é muito doido." (Reunião das Senhoras de Côr, Nair Pinheiro, documento 02.04.4254, 1951, p.1, sic, grifo no original). Em seguida, o item descrito é "Relações com amigos" e a pessoa que entrevista se dirige à Maria Nascimento e a questiona sobre as relações com as pessoas desde a sua chegada à São Paulo que ocorrera há três meses daquele encontro. A pergunta refere-se a diferenças de "comportamento" entre homens, mulheres e pessoas "mestiças" a qual afirmou "sentir isolamento" (Reunião das Senhoras de Côr, Maria Nascimento, documento 02.04.4254, 
1951, p. 6). Essas afirmações se referem aos modos como as concepções raciais impactam nas relações íntimas entre as pessoas. As questões sobre isolamento apontadas naquele período têm sido, na contemporaneidade discutidas em torno dos relacionamentos afetivos a partir do recorte racial.

Posteriormente, os questionamentos se voltam para as relações na infância, experiência que Nair Pinheiro retrata que a mudança de posição social afetava amizades que porventura tivessem se realizado na infância: "Às vezes a posição social separa. A convivência muda. Aquelas que continuam no mesmo plano, não" (Reunião das Senhoras de Côr, Nair Pinheiro, 1951, p. 6). Em seguida discute ${ }^{17}$ a dificuldade na educação das crianças, a Professora Maria Nascimento afirma que a existência do preconceito racial impacta diretamente a formação das crianças: 'Eu tentei internar no Asilo ‘Bom Pastor' uma menina. Lá elas entram com 13,14 anos e saem com 21. Não consegui porque era preta. O Colégio não aceita. A Criança de côr tem que continuar no abandono" (Reunião das Senhoras de Côr, 1951, Maria Nascimento, documento 02.04.4254, p. 11, sic).

O Arlindo Veiga dos Santos relatou:

As crianças vem da rua falando cousas que viram nas amisades. Fizeram isso não me deixaram entrar, não vi o salão... Para a criança tem um valor imediato. No começo, não há de fato, depois vão aparecendo cousas que a criança não compreende. A existência do preconceito no ambiente, cria problemas para a mãe negra e mulata, o que não existe para as mães brancas (Reunião das Senhoras de Côr, documento 02.04.4254, Arlindo Veiga dos Santos, 1951, p. 11, sic).

Maria Nascimento em seguida complementa:

A criança está no colégio e começam: - negrinha daqui, negrinha dali. Chega em casa chorando dizendo: - Não vou mais ao Colégio! A mãe se vê forçada a tirar a escola. Procura noutro colégio e não aceitam crianças de côr. A mãe fica completamente sem meios de resolver o problema. Põe a criança para trabalhar. Desiste da educação da filha." (Reunião das Senhoras de Côr, Maria Nascimento, documento $02.04 .4254,1951$, p. $11-12$, sic).

Os trechos acima apontam para o reconhecimento de que as relações raciais são existentes e conflituosas na infância e como tais aspectos impactam diferentemente as crianças de acordo com seu pertencimento étnico-racial. Um olhar holístico para esses trechos e dos temas que atingem as mulheres negras, evidencia de forma elucidativa uma ordenação sistemática em torno da questão racial em várias esferas. Dito de outro modo, há nas falas das entrevistadas a comprovação de uma estrutura social racialmente organizada que 
impacta a vida profissional, pessoal e afetiva das mulheres negras. Tais apontamentos embora fossem explícitos ficaram circunscritos aos relatórios e às reuniões entre as mulheres negras sendo posteriormente retiradas das análises macro que utilizaram os dados do projeto.

\section{USOS DOS RESULTADOS DAS PESQUISAS}

"Êste estudo trata do problema da côr em S. Paulo" (BASTIDE e FERNANDES, 1955, p. 15), com estas palavras Roger Bastide e Florestan Fernandes apresentaram o livro Relações raciais entre negros e brancos em São Paulo, publicado em 1955 no qual exibe alguns resultados das pesquisas realizadas durante um ano de execução do Projeto UNESCO no contexto paulista. A frase sintetiza o objetivo da pesquisa, o "problema de côr" se dava pelos modos de construção e os efeitos do preconceito racial em São Paulo.

No que se refere à inspiração teórica, Bastide e Fernandes inspiraram-se na sociologia moderna de Durkheim acerca dos fatos sociais em uma dada realidade social (BASTIDE e FERNANDES, 1979, p. 139). Os autores se guiaram pela formulação durkheimiana de que as representações "individuais" eram do domínio da psicologia, ao passo que as representações "coletivas", seriam da esfera da sociologia. Dessa interpretação se apreende a indicação indicada de que as etapas de mapeamento das manifestações de preconceito racial utilizassem a psicologia que forneceria elementos para captar o comportamento de negros e brancos em relação social (BASTIDE e FERNANDES, 1979, p. 159).

Em vista disso, indicou-se o enfoque tanto na "análise da educação na escola, quanto em casa (BASTIDE e FERNANDES, 1979 , p. 162), ${ }^{18}$ nos grupos de folguedo, nos grupos de trabalho e nas demais situações de convivência humana" que possibilitariam identificar a "a função psíquica delas" (BASTIDE e FERNANDES, 1979, p. 162). Dentre outras técnicas descritas, destacam-se o método ecológico que consistia na análise de uma população específica situada em determinados bairros; a aplicação de questionários; desenvolvimentos de técnicas de coleta de informações como conversas "ocasionais com negros e brancos, durante os passeios, as corridas de taxi, as viagens de ônibus como se fôssem instantâneos das relações raciais em plena vida cotidiana” (BASTIDE, 1955, p. 12, sic) e, por fim, técnicas de entrevistas formais "dirigidas conforme plano previamente estudado, com diversas personalidades de côr, e 
brancas, englobando perguntas sôbre os diversos aspectos da situação econômica, profissional ou social dos negros e de suas relações com os brancos" (BASTIDE, 1955, p. 12, sic).

No prefácio do livro em 1955, Roger Bastide fez referência ao trabalho de Lucrécio: "O dr. Francisco Lucrécio fez uma comunicação especial, de muita importância, sobre a situação dos imaturos de côr em face das manifestações do preconceito de côr" (BASTIDE, 1955, p. 14, sic). O estudo de caso citado, a respeito das relações raciais entre as crianças, é descrito no documento "Relações entre crianças Brancas e Negras em Parques Infantis da Capital" "19 que trata da leitura da pesquisa empírica realizada por Francisco Lucrécio. Lucrécio, junto a outros intelectuais, idealizou e coordenou a Escola de Alfabetização da Frente Negra (1934-1937) voltada para adultos e crianças além de enveredar pela política ao candidatar-se a deputado federal.

As impressões de Francisco Lucrécio estão com a seguinte inscrição "Situação das crianças "negras" nos parques infantis" descrito como parte de um depoimento cedido à Renato Jardim Moreira descrito como "Estudos de Caso: Situação das Crianças 'negras' nos Parques Infantis". O depoimento é baseado em um trabalho de campo com uma análise pormenorizada acerca dos espaços destinados à educação das crianças pequenas que, imediatamente, parte das diferentes condições ofertadas às crianças negras e brancas.

Sobre os relatos acerca das crianças Roger Bastide afirmou a existência de "uma espécie de 'tabu da côr' que se aprende desde a infância; desenvolve-se na criança um duplo mecanismo de comportamento, paternalista com relação aos negros, igualitário com relação aos brancos, pelo menos aos brancos da mesma classe" (BASTIDE, 1955, p. 126). Essa leitura do impacto das relações e da orientação dos pais no desenvolvimento do preconceito racial se expressa também nas análises de Virgínia Bicudo. Bastide afirma ainda que essas experiências e as "brigas nas quais os meninos brancos fazem sentir ao preto a diferença de pele, que explicam o horror da criança de côr pela escola e levam os pais a afastar os filhos. É a primeira barreira informal. É preciso energia para transpô-la" (BASTIDE, 1955, p. 143, sic). Essa "energia" que deve partir dos pais de crianças negras segundo Bastide, não existe de modo imprevisto para eles, segundo outro depoimento: "Para educar uma criança, é necessária tôda uma ciência [...], mas para educar uma criança de côr, uma ciência e meia... Vejo o meu filho chegar da escola sempre cheia de raiva. Tenho de acalmá-lo, dizer-lhe que aceite" (BASTIDE, 1955, p. 144, sic). 
Após as descrições dos casos Lucrécio concluiu que "tudo o que eu disse é para provar que o preconceito começa desde os bancos escolares" (Relações entre crianças brancas e negras em parques infantis da capital, documento 02.04.4527, Francisco Lucrécio, s/d, p. 196, sic). Pesquisas contemporâneas sobre as práticas de professoras e professores na educação infantil evidenciaram a existência de um tratamento diferenciado dado às crianças brancas e negras cujos efeitos são nefastos na subjetividade das crianças negras e brancas (CAVALLEIRO, 2007; OLIVEIRA, 2004). As descrições realizadas por Francisco Lucrécio são elucidativas não apenas pelos dados que informam, mas pelas análises empreendidas nas quais o autor se coloca diante dos fatos que observa. Gilca Ribeiro Santos (2013) afirma que a educação na prática de intelectuais e nas associações negras representavam uma ação modernizadora para a população negra. É importante destacar que a educação sempre foi uma pauta do movimento negro. Em suas várias vertentes e diferenças internas o acesso à educação e as distintas ações para autoeducar-se estão na história do movimento da população negra.

\section{CONSIDERAC̣ÕES FINAIS}

As pesquisas contemporâneas que buscam estabelecer genealogias históricas da pesquisa sobre o protagonismo da população negra sobre sua condição e, de modo específico, nas experiências históricas de educação elaboradas e vivenciadas por negros e negras adquiram destaque ao atestar uma lacuna no modo pelo qual a história da educação brasileira é narrada. Isso ocorre não apenas em razão de que há um modo pelo qual a história é contada que ignora a existência de práticas pedagógicas elaboradas pela população negra que exclui a contribuição da população negra do processo histórico de constituição da educação brasileira. Isso, no entanto tem se modificado com qualificadas pesquisas inseridas no campo acadêmico.

É importante salientar que o pensamento sobre o cuidado a respeito da condição das crianças e das mulheres negras foram permanentes no interior de distintas associações e entidades do movimento negro. A assistente social Maria de Lurdes Nascimento organizou o Conselho das Mulheres Negras que no interior do Teatro Experimental do Negro em 1950 consistia em um departamento dedicado às problemáticas das mulheres negras ${ }^{20}$ (ROMÃO, 2003). O Conselho das Mulheres Negras desenvolveu ainda uma linha de atenção jurídica às mulheres negras e obtinha certidão de nascimento para as crianças. Com participação atuante 
nessas questões Maria torna-se responsável pela coluna Fala Mulher do Jornal O Quilombo, entre 1948 e 1950, em uma das edições afirma:

Queridas leitoras e amigas volto mais uma vez a falar das nossas crianças.... Essa infância precocemente adulta pela promiscuidade e pela necessidade de trabalhar... é em sua quase totalidade de cor.... O coeficiente de mortalidade infantil no Distrito Federal entre 1939-1941... segundo estatísticas do Departamento Nacional da Criança... morrem quase duas crianças de cor por uma branca. Na cidade de São Paulo a situação é ainda mais grave (NASCIMENTO, M. L. Jornal O Quilombo, 1949, p. 2).

Maria de Lourdes do Nascimento alerta: "Nada de desânimo quando uma maternidade nos negar ingresso. Devemos usar todos os meios e remover todas as dificuldades, ainda mesmo que sejam motivadas por discriminação de cor...” (NASCIMENTO, 1949). Em outra edição da coluna incita a importância da participação das mulheres nas atividades políticas como o voto:

Se nós mulheres negras do Brasil, estamos mesmo preparadas para usufruir os benefícios da civilização e da cultura, se quisermos de fato alcançar um padrão de vida compatível com a dignidade da nossa condição de seres humanos, precisamos sem mais tardança fazer política.... Precisamos constituir um exército de eleitoras pesando na balança das urnas, usar o máximo as franquias democráticas que nos asseguram o direito que é também o sagrado dever cívico de votar e sermos votadas para qualquer pleito eletivo nas próximas eleições de 3 de outubro (NASCIMENTO, 1950).

A preocupação com as mulheres negras e as crianças negras se fazia sempre presente:

É inacreditável que numa época em que tanto se fala em justiça social possa existir milhares de trabalhadoras como as empregadas domésticas, sem horário de entrar e sair do serviço, sem amparo na doença e na velhice, sem proteção no período de gestação e pós parto sem maternidade sem creche para abrigar seus filhos durante as horas de trabalho (NASCIMENTO, M. L. 1949, p. 2).

Tais afirmações revelam uma preocupação com a condição social a qual estavam submetidas mulheres e crianças negras, e ainda a compreensão do espaço da luta política como possibilidade de transformação de tal condição.

Ao cotejar as pesquisas e, principalmente as falas das mulheres e homens negros que participaram ativamente da elaboração e desenvolvimento do Projeto UNESCO em sua etapa paulista identificamos o pioneirismo que agregam por articularem, já a partir da década de 1930 até a década de 1950, categorias de análise como raça, gênero, nacionalidade, faixa etária e classe social entre outras.

Em relação aos caminhos abertos pela trilha aqui traçada, verifica-se a necessidade de fomentar pesquisas sobre a investigação das crianças e a participação das mulheres negras que, como se viu, foram extremamente ativas no Projeto UNESCO. Certamente 
há possibilidade de ampliar o escopo dos objetos de pesquisa estabelecendo conexões interdisciplinares entre diferentes áreas e que nos permitirão, tal qual foi aqui estabelecido, de estabelecer novos delineamentos à essas histórias. Dito de outra forma, é necessário recuperar as propostas e sugestões dos sujeitos negros que pautaram as pesquisas sobre a constituição das questões raciais no Brasil. Tal ação permitirá rever as incúrias vertidas na constituição do pensamento social brasileiro. Especialmente a participação efetiva das mulheres habitam um incabível ostracismo, seja nas pesquisas sociológicas que retomaram os resultados das investigações resultados das investigações do Projeto UNESCO sejam nas pesquisas sobre a educação. No que tange às pesquisas históricas sobre as experiências da população negra com sua educação no Brasil, ao tomarmos os dados produzidos identificamos que são grande envergadura para uma ampliação temporal nas experiências educacionais dedicadas às crianças negras e à condição das mulheres negras. O lampejo de luz aqui lançado nas mulheres que atuaram nas pesquisas e nas preocupações sobre as crianças negras nos faz repensar e refazer aquilo que emerge do debate sobre reconhecimento.

Tal ação reverbera de outros projetos políticos e teóricos. Os anos 1960 marcaram o debate sobre o colonialismo junto a uma internacionalização dos denominados estudos africanos, da produção de uma história da África escrita por pessoas africanas, da causa pan-africana pautada por críticas ao modo de construção das ciências antropológicas e às narrativas histórias que atuaram no colonialismo. Isso foi especialmente importante, pois no momento em que dezesseis países africanos adquiriram independência, o panafricanismo consolidava-se como "um conjunto de relações unindo os africanos além das suas fronteiras territoriais" (MAZRUI, 2010, p. 1106). Essa proposta já se delineava quando da criação da Societé Africaine de Culture (1949) que, por meio da revista "Presence Africaine", 21 colocava como pauta política a elaboração de uma "história da África descolonizada" este intento é a origem da posterior elaboração do projeto História Geral da África (HGA), (KI-ZERBO, 2010, p. 20).

Angela Davis (2017) afirmou que a constituição dos "estudos étnicos" nos EUA configurou-se como um movimento mais amplo na luta pela ampliação da justiça e igualdade, na medida em que no decurso da: "evolução do movimento de libertação afro-americana, desde a época da escravidão até o presente, a batalha pela educação tem sido o próprio coração da busca pela liberdade" (DAVIS, 2017, p. 159). Esses exemplos junto a outros marcam não apenas a constituição de campos acadêmicos, mas de posições políticas. 
O debate acerca do reconhecimento na via de outra proposição intelectual interpela as categorias centralizadas em diversas disciplinas, sobretudo nas ciências humanas. Frantz Fanon $(2008 ; 2010)$ apontou que o colonialismo representou o ápice de uma prática insidiosa cuja negação da humanidade para homens e mulheres negras não apenas constituiu produto de tal prática, mas acima de tudo seu modo de sustentação.

Achile Mbembe (2010) considera que a "política do futuro" está sustentada em questionamentos acerca das relações entre a convivência e a diferença diante da globalização/mundialização. A compreensão de que a configuração política da contemporaneidade é circunscrita por distintos cosmopolitismos ou transnacionalidades dirige-nos diretamente às questões colocadas pelo debate transnacional. Tal debate ainda em curso tem modificado as bases epistemológicas do pensamento sobre a nação e, por conseguinte, da identidade nacional. Se havia uma concepção fechada de identidade nacional em elementos intransferíveis como o território e a língua como elementos que caracterizariam a identidade de um povo, isso não tem ocorrido de forma tão simples. As experiências diaspóricas modificaram tais arranjos tornando, de acordo com a conjuntura histórica, mais fluidas ou mais concretizadas as identificações nacionais. Para Avtar Brah, a diáspora corresponde a uma categorização analítica que traz determinadas delineações que, em certo sentido, desarticulam o modo pelo qual a nação tem sido pensada. A diáspora auxilia a compreensão das diferentes formas pelas quais as pessoas se movimentam, assim é possível descrever as genealogias que considerem o social, a subjetividade e a identidade (BRAH, 2011, p. 211). Dito de outra forma, as experiências de povos que vivenciaram diferentes tipos de diásporas - ocorridas por diversas razões - negociam suas identidades, mudando os territórios, subvertendo as línguas e forjando novas concepções de povo. Tal cenário tem um impacto direto no esquema das Nações Unidas.

Em 2001, a UNESCO publicou algumas metas denominadas de "marcos de ação" a serem realizados no Brasil. Ao adotar mutações decorrentes da "nova ordem global" afirma que, em meio às mudanças globais, seu papel "reside no fato de que suas ações nascem no consenso dirigido em meio à diversidade radical de 186 países em todo o mundo" (UNESCO, 2001, p. 24). No mesmo texto, destaca que a "UNESCO de hoje é foro mundial para que a comunidade internacional dê significado em consciência ao ambíguo processo de globalização" (UNESCO, 2001, p. 24).

O lançamento do nono volume da HGA em 2013 em Adis Abeba terá como tema central a "Diáspora Africana" sob diversas 
perspectivas, como a dispersão em diferentes momentos históricos, do tempo antigo à colonização em variadas partes do mundo, o tráfico de escravizados africanos e as experiências de descolonização. Epistemologicamente, o nono volume da HGA se apoia no conceito de "Africanidade global" elaborado como um projeto de ruptura epistemológica ao incorporar as diversas formas de dispersão de africanos e seus descendentes. O que se configura como "Africanidade global" é uma espécie de genealogia da experiência das populações africanas e seus descendentes no espaço da diáspora. A proposta insere e articula as diferentes motivações, contextos e consequências das diásporas africanas na longa duração e em sua diversidade.

A subvenção da UNESCO no contexto brasileiro constituiu uma dispendiosa intercessão por meio de indicações normativas, projetos e publicação de materiais didáticos, livros, pesquisas estatísticas e diagnósticas em âmbito acadêmico sobre a temática racial nos últimos anos. A Década Internacional de Afrodescendentes entre 2015 e 2024 da Organização das Nações Unidas (ONU), cujo tema é "reconhecimento, justiça e desenvolvimento" está diretamente associado aos esforços empreendidos para recompor a história e o protagonismo da população negra. Nas atividades no âmbito do reconhecimento, a ONU insta os países a desenvolverem ações que visem "inclusive através de pesquisa e educação, e promover a inclusão completa e precisa da história e da contribuição dos povos afrodescendentes nos currículos escolares". ${ }^{22}$

Michel-Rolph Troillou (2016) afirma: "nossa autenticidade se baseia nas lutas do nosso presente" (TROILLOU, 2016, p. 240). Esse historiador haitiano conclama a necessidade de expor as raízes do modo de uso do vernáculo história, pois segundo ele, a história se faz entre o que ocorreu e o modo como se narra o que ocorreu. Para ele, a terminologia utilizada na descrição de um acontecimento demarca as relações de poder que fundam os silêncios e as falas em torno desse acontecimento, afirmando que "a autenticidade histórica reside não na fidelidade a um pretenso passado, mas na honestidade em face do presente, uma vez que ele re(a)presenta o passado" (TROUILLOT, 2016, p. 236). Tal proposição é fundamental. É no campo de "como se narra o que aconteceu" que as perspectivas de reconhecimento se baseiam e onde os relatos aqui apresentados se localizam. Aqui se encontram as fronteiras metodológicas e teóricas da escrita da história. Do uso e escolha das fontes das quais se produzem os dados históricos. Esse debate se insere na construção de uma nova agenda de investigação (HOUNTONDJI, 2008) que pressupõe outra base 
epistemológica, que se aproprie de saberes locais para que se pretenda constituir pontos de conexão em um debate global (ADESINA, 2008). Isso permitirá como na perspectiva de Zeleza (2005), se debruçar na historiografia, sobre como a história da população africana e de seus descendentes na diáspora tem sido estudada e produzida.

Beatriz Nascimento questiona: "Como fazer, como escrever a História sem se deixar escravizar pela abordagem da mesma, fragmentariamente?" (NASCIMENTO, [1974] 2006). Tal questionamento não se baseia em um presenteísmo banal cujo corolário é o receio ao anacronismo, mas de compreender, cada narrativa como um tipo de retórica da qual se denominam os tropos (WHITE, 1994). Faculta-nos colocar de modo articulado acontecimentos históricos e encontrar os momentos em que "conversam" e por quais vozes esse diálogo ecoa em nós no "tempo disjuntivo" (BHABHA, 2007, p. 247) da contemporaneidade. Em outras palavras, reconhecer o protagonismo desses homens e mulheres negras, requer que nos coloquemos para ouvir como expuseram suas subjetividades nos permitindo apreender suas presenças em um espaço coletivo. Pressupõe inseri-las em um ângulo de uma "Africanidade global" que se espraia pela diáspora negra. Se ocupa de apreender a presença de corpos negros em um tecido social cuja organização racial é reveladora de uma herança que atravessa a constituição da história brasileira. Ao analisar as variadas formas de construção de um texto histórico, um determinado discurso ou imagem nos oferece um repertório de sentidos sobre uma determinada coisa ou pessoa em outras temporalidades. Esse movimento nos levará a equacionar reconhecimento com justiça e desenvolvimento quando as vidas desses homens e mulheres e crianças negras forem ressignificadas a partir de suas experiencias de luta e resistência.

\section{REFERÊNCIAS}

ADESINA, J. Archie Mafeje and the pursuit of endogeny: against alterity and extroversion. Africa Development, v. 33, n. 4, p. 133-152, 2008.

AZEVEDO, C. M. M. Onda Negra, Medo Branco: o negro no imaginário das elites do século XIX. Rio de Janeiro: Paz e Terra, 1987.

BASTIDE, R. \& FERNANDES, F. Brancos e negros em São Paulo: ensaio sociológico sobre aspectos da formação, manifestações atuais e efeitos do preconceito de cor na sociedade paulistana. São Paulo: Global, 2008.

BASTIDE, R. \& FERNANDES, F. O preconceito racial em São Paulo; projeto de estudo. In: HIRANO, S. Pesquisa social: projeto e planejamento. (org.) Capítulo 6. p. 135-166, 1979. 
BASTIDE, R. Les relations raciales au Brésil : Les noires aux États-Unis d'Amérique. Bulletin international des sciences sociales, v. IX, n. 4, p. 525-548. 1957.

BRAH, A. Cartografías de la diáspora: identidades en cuestión. Trad. Sergio Ojeda. Madrid: Traficantes de Sueños, 2011.

CAMPOS, A. J. M. Interfaces entre sociologia e processo social: A Integração do Negro na Sociedade de Classes e a pesquisa Unesco em São Paulo. Dissertação de mestrado em sociologia. Campinas, SP, 2014.

CRUZ, A. C. J.; ABRAMOWICZ, A.; RODRIGUES, T. C. A pesquisa sobre criança e infância no Projeto UNESCO. Revista Eletrônica de Educação (São Carlos), v. 9, p. 321-345, 2015.

DOMINGUES, P. Frentenegrinas: notas de um capítulo da participação feminina na história da luta anti-racista no Brasil. Cad. Pagu, Campinas, n. 28, p. 345-374, June, 2007.

DUARTE, P. Negros do Brasil. OESP. 16-17 de abril, 1947.

FERNANDES, F. O negro no mundo dos brancos. São Paulo: Difusão Européia do Livro, 1972.]

HOUNTONDJI, P. Duas perspectivas de estudos africanos. Revista Crítica de Ciências Sociais, n. 80, p. 149-160, mar. 2008.

LEITE, J. C. O Esgar do Sr. Paulo. Duarte. Alvorada, São Paulo, ano III, n. 25, 13 mai. 1947.

MAIO, M. C. Educação sanitária, estudos de atitudes raciais e psicanálise na trajetória de Virgínia Leone Bicudo. Cad. Pagu, Campinas, n. 35, p. 309-355, Dec. 2010.

MAIO, M. C. A história do Projeto Unesco: estudos raciais e ciências sociais no Brasil. Rio de Janeiro. Tese de doutorado em Ciência Política. Instituto Universitário de Pesquisas do Rio de Janeiro (Iuperj), 1997.

MAUREL, C. Le rêve d'un gouvernement mondial : des années 1920 aux années 1950: l'exemple de l’UNESCO, Histoire@Politique: Politique, culture, société, n. 10, janvier-avril, 2010.

NASCIMENTO, A. O negro revoltado. $2^{a}$ ed., Rio de Janeiro: Nova Fronteira, 1982 [1968].

NASCIMENTO, B. Por uma história do homem negro. In: RATTS, A. Eu sou atlântica. $1^{a}$ ed. São Paulo: Imprensa Oficial/Instituto Kuanza, 2007. v. 1.136p.

NASCIMENTO, M. L. Coluna Fala Mulher. Jornal Quilombo. Ano II. n. 6, Rio de Janeiro, Junho de 1949.

PAIXÃO, M. A lenda da modernidade encantada: por uma crítica ao pensamento social brasileiro sobre relações raciais e projeto de Estado-Nação. $1^{\text {a }}$ ed. Curitiba-PR: Ed CRV, v. 1. 473 p., 2013.

PAIXÃO, M. Crítica da razão culturalista: relações raciais e a construção das desigualdades sociais no Brasil. Tese de doutorado em Sociologia: Instituto universitário de pesquisas do Rio de Janeiro. Iuperj, Rio de Janeiro, 2005.

PARK, R. Introdução à $1^{a}$ Edição americana, in: PIERSON, D., Brancos e pretos na Bahia, São Paulo, Cia. Editora Nacional, p. 79-86. 1971. 
ROMÃO, J. Educação, instrução e alfabetização de adultos negros no Teatro Experimental do Negro. In: História da Educação dos Negros e Outras Histórias. Brasília: Ministério da Educação, Secretaria de Educação Continuada, Alfabetização e Diversidade, p. 117-137, 2005.

SANTOS, G. R. O pensamento educacional de Francisco Lucrécio e Ironides Rodrigues. 2013. 121 f. Dissertação Mestrado em Ciências Humanas. Universidade Federal de Uberlândia, Uberlândia, 2013.

TROILLOU, M-R. Silenciando o passado: poder e a produção da história. Tradução de Sebastião Nascimento. - Curitiba: Huya, 2016.

VALLA, V. V. Educação, participação, urbanização: uma contribuição à análise histórica das propostas institucionais para as favelas do Rio de Janeiro, 1941-1980. Cadernos de Saúde Pública, Rio de Janeiro, v. 1, n. 3, p. 282-296, Set. 1985.

L'UNESCO : ce qu'elle est, ce qu'elle fait: La maison de l'unesco. O Correio da UNESCO, Ano XI, nº 11, p. 37-38, 1958.

UNESCO. Bref historique sur le concept de la culture de la paix. UNESCO: Paris 2000, 3p.

UNESCO. La UNESCO et son programme : la question raciale. 1950, 11p.

UNESCO. O Correio da UNESCO, Ano III, No 8, p. 8, 1950.

WHITE, H. Trópicos do discurso: ensaios sobre a crítica da cultura. Trad. Alípio Correia de Franca Neto. São Paulo: Edusp, 1994.

WEST, C. Questão de raça. Trad. Laura T. Motta. São Paulo: Companhia das Letras, 1994.

ZELEZA, P. T. Banishing the silences: towards the globalization of African history. Dakar: CODESRIA, 2005.

\section{NOTAS}

${ }^{1}$ Aprovada na $5^{\text {a }}$ Assembleia Geral das Nações Unidas de Florença em 1950 na sessão do ECOSOC na qual foi indicado à UNESCO "pesquisar e reunir os dados científicos concernentes às questões raciais; difundir amplamente os dados científicos assim reunidos e preparar uma campanha de educação baseada nestes dados" (O Correio da UNESCO, 1950, Ano III, No 8, p. 8).

${ }^{2}$ Cf.: DUARTE, P. Negros do Brasil. O Estado de São Paulo, 16-17 de abril de 1947.

${ }^{3}$ Fernandes descreve como uma investigação sociológica sobre "a situação de contato entre negros e brancos na cidade de São Paulo" visto que a cidade seria o exemplo do "Brasil moderno" (FERNANDES, 1972, p. 197), com o objetivo de realizar um "ensaio sociológico sôbre as origens, as manifestações e os efeitos do preconceito de cor no município de São Paulo” (UNESCO - Anhembi, Editôra Anhembi Limitada, São Paulo, 1955, sic).

${ }^{4}$ As falas são descritas antecedidas do nome de quem as profere e em parênteses há uma definição racial (branco, preto, mulato, mulato claro). 
${ }^{5}$ Optou-se por manter os termos literais assim como dos nomes das pessoas. Para demarcação desta opção ao final de cada citação há a descrição do documento (se uma mesa redonda, palestra etc.), em seguida, o nome da pessoa que profere a fala, posteriormente o número do documento localizado no Fundo Florestan Fernandes e a página do PDF.

${ }^{6}$ A história de Virgínia Leone Bicudo está analisada na tese: GOMES, Janaína Damasceno. Os segredos de Virgínia: estudo de atitudes raciais em São Paulo 1945-1955. Tese de doutorado em Antropologia Social. São Paulo, USP, 2013.

${ }^{7}$ Embora tenha sido descrita como "branca" em seu registro de trabalho na Escola Livre de Sociologia e Política (MAIO, 2010) Virgínia Bicudo, sendo filha de mãe branca ("imigrante pobre de origem italiana") e pai negro (“descendente de escravo").

${ }^{8}$ Visando evidenciar "os sentimentos e os mecanismos psíquicos de defesa manifestos nas atitudes relacionadas com a côr dos colegas; e a influência das relações intrafamiliais no desenvolvimento daquelas atitudes" (BICUDO, 1955, p. 227, sic). Uma primeira versão deste texto é publicada em 1953, posteriormente é publicado no livro organizado por Florestan Fernandes e Roger Bastide Relações raciais entre brancos e negros em São Paulo em 1955.

${ }^{9}$ Gisberg foi professora de psicologia social na ELSP entre 1937-1940.

${ }^{10}$ Ginsberg descreve os grupos de escolares compostos por "crianças pobres operárias e artesãs", "crianças filhos de operários de nível econômico mais elevado" e, por fim, "crianças de uma escola particular [...] filhos de ricos" (GINSBERG, 1955, p. 315, sic).

${ }^{11}$ Após debates para a definição da composição das comissões a Comissão de Redação foi composta por Geraldo Campos de Oliveira, Luiz Lobato, Jorge Prado Teixeira, José Correia Leite, Mário Vaz Costa, Raul Amaral e Francisco Moraes (2a Mesa Redonda, documento 02.04.4531, 1951, p. 64, sic).

${ }^{12}$ Quinta mesa redonda sôbre o Preconceito Racial no Brasil, realizada no Salão Nobre da Faculdade de Filosofia Ciências e Letras da Universidade de São Paulo, no dia 26 de julho de 1951, patrocinada pela UNESCO sob a presidência do prof. Arlindo Veiga dos Santos $\left(5^{\mathrm{a}}\right.$ mesa redonda, documento $02.04 .4531,1951$, grifo no original).

${ }^{13}$ Maria Rosário, Loreni Santos, Benedita de Barbosa e de participantes da "comunidade branca" a profa. Maria Isaura Pereira de Queiroz e Maria Helena Barbosa, como estudantes. (2 $2^{\mathrm{a}}$ Mesa Redonda, Roger Bastide, documento 02.04.4531, 1951, p.84).

${ }^{14}$ Documento da Reunião das senhoras de cor, realizada na FFCL da USP. Mimeo, 14 ago. 1951. Reunião com Mulheres do Fundo Florestan Fernandes disponibilizado no arquivo PDF 02.04.4534, (BCo/UFSCar), p. 1-13.

${ }^{15}$ A Fundação Leão XIII criada pelo governo federal em articulação com a Igreja Católica em 1946, compunha uma série de medidas assistencialistas e atuou na função de ser um órgão articulador das políticas de assistência social no Estado do Rio de Janeiro. Dentre as suas funções estava a de "prestar assistência moral, material e religiosa aos habitantes dos morros e favelas do Rio de Janeiro" (VALLA, 1985).

${ }^{16}$ Escola fundada em 1932 localizada no bairro da Água Branca, região oeste da cidade de São Paulo. 
${ }^{17}$ Pergunta feita a Professora Maria Nascimento: "Há mais dificuldade em educar os filhos, para a mãe preta que para a mãe branca, tendo em vista todos os fatores econômicos e a existência ou não do preconceito? Afirmado o preconceito pela Senhora a existência de preconceito reflete-se nos pais, na dificuldade que a mãe preta tem para educar os filhos?" (Reunião das Senhoras de Côr, 1951, p.11, sic).

${ }^{18}$ Grifo no original.

${ }^{19}$ Estudos de Caso: Situação das Crianças “negras” nos Parques Infantis. Documento 4527, Depoimento: Francisco Lucrécio - escrito por Renato Jardim Moreira.

${ }^{20} \mathrm{O}$ departamento feminino do TEN “com o nome de Conselho das Mulheres Negras [com] Ensino profissional: criação de Escola de Artes domésticas [...] proteção à infância, com criação de abrigos para crianças negras [...] Educação da infância [...] jardim de infância, teatro infantil, teatro de bonecos (...) Irá funcionar imediatamente os seguintes setores [...] Educação e Instrução - Vários cursos, desde alfabetização até o ginásio" (ROMÃO, 2003).

${ }^{21} \mathrm{O}$ primeiro número define o objetivo da revista, escrito por André Gide de não se submeter a qualquer ideologia ou política e se abrir para "definir a originalidade africana e acelerar sua inserção no mundo moderno” (GIDE, A. Presence Africaine, 1947).

${ }^{22}$ Década Afrodescendente, Plano de ação. http://decada-afro-onu.org/plan-action.shtml, acesso em: 20 jul. 2018.

Submetido: 06/02/2018

Aprovado: 05/08/2018

Contato:

Universidade Federal de São Carlos (UFSCar) Departamento de Teorias e Práticas Pedagógicas $(\mathrm{CECH})$ Rod. Washington Luís, km 235 SP-310, sala 7 - Bairro Monjolinho São Carlos |SP|Brasil CEP 13.565-905 